\title{
The Viewpoint of the Uselessness of Vocational Qualification Certificate: Analysis and Solution
}

\author{
Yuhuang Zheng ${ }^{1,2, *}$ and Lin Chen ${ }^{1}$ \\ ${ }^{1}$ Department of Physics and Information Engineering, Guangdong University of Education, Guangzhou, China \\ ${ }^{2}$ Guangdong Province Key Laboratory of Precision Equipment and Manufacturing Technology, Guangzhou, China \\ ${ }^{*}$ Corresponding author
}

\begin{abstract}
The uselessness of vocational qualification certificate" is a social trend of thought that the effectiveness of vocational qualification certificate has dropped due to the failure of the trainees' skill training investment. The main causes are society and enterprises development, training institutions' teaching factors and trainees' understanding of vacation qualification certificate and so on, involving stakeholders such as government, enterprises, training institutions and trainees. It is necessary for government departments, enterprises, training institutions and trainees to work together to improve the social influence and effectiveness of vocational qualification certificates and to break the false proposition of this viewpoint.
\end{abstract}

Keywords-electrician technician; statistical analysis; vocational qualification certificate

\section{INTRODUCTION}

The viewpoint of the uselessness of vocational qualification certificate is on the rise in civil life with the vigorous promotion of national training for high skilled talents. Because of the decline in the effectiveness of vocational qualification training, many trainees have the thought of the uselessness of vocational qualification certificate. The emergence of this idea reflects the acceleration of social development and the improvement of individual quality to a certain extent, but if the idea of this viewpoint continues to spread, it will bring negative consequences to the cultivation of high skilled talents in China [1]. Therefore, it is urgent to analyze the causes of "the uselessness of vocational qualification certificate" and put forward relevant coping strategies.

\section{Statistical ANALysis Of QUestionnaire SuRVEy DATA}

The data of this paper is from the network questionnaire survey performed by a vocational skill identification Institute of a provincial key engineering college and university and a training institution in Zhuhai city on the trainees who got the vocational qualification certificates of maintenance electrician and senior maintenance electrician from 2013 to 2018. A total of 113 trainees participated in the survey.

According to the survey results, the trainees who have got the vocational qualification certificates of maintenance electrician and senior maintenance electrician are not very positive. The number of the trainees who were trained by the two training institutions mentioned above and got the vocational qualification certificates of maintenance electrician and senior maintenance electrician from 2013 to 2018 is not less than 1100, but the number of respondents to the questionnaire is less than $1 / 2$. In addition to the lack of time for some trainees to use the Internet, most of the trainees are not actively involved. It can prove that they are generally not concerned about the matters related to vocational qualification certificate.

According to the survey results, the proportion of trainees that consider "very useful and making me improved obviously" is nearly $40 \%$, which indicates that the current training in Maintenance Electrician and Senior Maintenance Electrician is generally good and many trainees recognize the training courses and corresponding vocational qualification certificates. However, the proportion of trainees that consider "a little useful" is $30 \%$ and the proportion of trainees that consider "uselessness" is nearly 30\%. It is noteworthy that more than 5\% of trainees believe that obtaining vocational qualification certificates is a waste of money and time. In other words, almost $1 / 3$ of the trainees who hold the affirmative, preservative and negative attitude towards the promotion of maintenance electrician and senior maintenance electrician certificates. This is a very thoughtful phenomenon, showing that there are many problems in the current maintenance electrician and senior maintenance electrician training. The reasons for this phenomenon will be analyzed as follows.

\section{PHENOMENON ANALYSIS}

\section{A. Social Factors}

\section{1) Policies and regulations}

At present, the government makes great efforts to the high skilled talents. For example, according to "the notice on adjusting basic pensions for enterprises retirees in 2013" published by the Guangdong provincial Bureau of human resources and social security and Guangdong provincial department of finance, the senior technician of this province will receive an additional 800 yuan of government subsidy after retirement. For trainees who have obtained vocational qualification certificates, there will be a corresponding onetime subsidy. However, many students don't recognize vocational qualification certificates. At present, there is no formal policy for the treatment of technicians and senior technicians. The welfare treatment of technicians and senior technicians can be determined referring to the benefits of 
professional and technical personnel such as engineers and senior engineers according to only a few policy documents of the 90s of the last century. Although some provinces and cities have designated some relevant laws and regulations, the technicians and senior technicians with vocational qualifications are still not respected and even discriminated against in the society. For example, when declaring scientific and technological projects and all kinds of high-tech enterprises, one of the measurement of the level of personnel in the declaration material is the title structure. Only engineers and senior engineers will be approved by the current title system and technicians and senior technicians will be ignored. The vocational qualification certificates will be recognized within a certain range by colleges or schools of vocational and technical, and never be recognized by ordinary secondary schools and common colleges and universities. This problem is essentially a docking between vocational qualification grade and professional technical title. The government has already solved some problems from retirement treatment and also promotes and supports the development of qualification certification for technicians or senior technicians in all fields of society. The problems of full docking between vocational qualification grade and professional technical title for the serving staff can't be solved by the existing personnel system. After there is the same social influence between vocational qualification grade and professional technical title, the gold content of vocational qualification certificates will be improved. Students will have a sense of identity and pride in their vocational qualification certificates.

\section{2) Employment system of enterprise}

After the examination and evaluation of technicians and senior technicians implemented the social management, the system of evaluation and employment is carried out, that is, the personnel having obtained vocational qualification certificates of technician or senior technician are appointed by the employer. The appointment of technicians and senior technicians should be combined with the needs of production posts and labor management. Enterprises set up technicians and senior technician positions and quantities according to their needs. The appointment is given when there is posts for the applicants with technician qualification. The appointment isn't given when there is no posts for the applicant with technician qualification. However, many enterprises, especially some small and medium enterprises, have no definite employment system for technicians and senior technicians. It easily results in the viewpoint of the uselessness of vocational qualification certificate by the workers of such enterprises.

\section{3) Devaluation of vocational qualification certificate}

Because of the impact of the macroeconomic situation and the fast-changing market demand ${ }^{[2]}$, the employers have put forward more and more demands on the actual working skills and the ability to adapt to the change of the working environment of technicians and senior technicians. The examination content of vocational qualification certificate often lags behind the development of enterprise technology, which leads to the difference between the talent requirement of enterprise and the examination content of vocational qualification certificate, and the situation of not qualified for the corresponding post after obtaining vocational qualification certificate. The devaluation of the educational effectiveness of technician and senior technician certificates with the rapid development of high technology mainly reflects in the fact that the knowledge of learning is not enough for practical use. The training institution is a place for students to systematically study the professional knowledge and skills for corresponding vocational qualification certificates. However, the value of vocational qualification certificate has depressed with the development of kinds of new technology and new requirements in the society. This will also reduce students' attention to vocational qualification certificates.

\section{B. Teaching Level and Facilities of Training Institutions Uneven}

1) The level of teachers in some training institutions not high

The government has clear standards for the training institutions of technicians and senior technicians and in general, teachers also have corresponding vocational qualification certificates and examiner certificates. The actual teaching effects are different among teachers due to different personal knowledge background and teaching style. Many teachers only explain the knowledge for examination, don't teach the content systematically, and don't teach how to find the way of solving problems in class. There are also a small number of teachers making simple questions very complicated and misleading the students. Even more, there are a few teachers never teaching, but only giving so-called examination question bank that they have sorted out to students and making them memorize. Students cannot get any inspiration and any useful knowledge from such teaching.

A good teacher, teaching the courses for high skilled talents, must have a deep love for vocational education and a sense of responsibility for the growth of these technicians. He must regard the cultivation of high skilled talents as his occupation and career. He must keep pace with the times, stand in the forefront of high and new technology, read the first hand technical data of the high and new technology, grasp the practical application and operation of the high and new technology, study the problems in practical work persistently, and make further expansion and in-depth discussion. Such teachers have a solid foundation of knowledge, have a unique teaching method, and can impart the whole knowledge system to the students, so that they can get the students' love.

\section{2) Imperfect experimental facilities in some training} institutions

For practical training, many equipment in the training of technicians and senior technicians are divorced from and far from the actual situation of enterprises at present. In order to save the cost of teaching, some training institutions let several students train in one station, which leads to the lack of training time for the students, and the difficulty in controlling the teaching process for the teachers. The students complain, and the teachers are exhausted. If a device failed in normal use during its operation will increase the burden on teachers and trainees. Therefore, the training organization should ensure one trainee and not more than two trainees in one work position, and at least one work position prepared. 


\section{Students' Own Factors}

In addition to the above objective reasons, the students' own factors cannot be ignored.

\section{1) Lack of motivation for self promotion by learning}

At present, the trainees participating in the training of technicians are generally not high in the level of education, mainly from technical secondary school and colleges. The trainees for senior technicians are better in the level of education, but also mainly from colleges. Therefore, their knowledge structure is relatively narrow, and they are not good at getting useful information. Generally, the ability of language expression, logical thinking and self-learning is relatively weak, which leads to the lack of learning motivation. They are often satisfied only with the knowledge explained by teachers in class. They do not want to learn or even know about the relative knowledge. They only focus on the narrow knowledge required in their jobs, or the examination points of vocational qualification certificates. Once there are some new problems in the practical work, they will be helpless, and then they will complain of not acquiring much knowledge by obtaining vocational qualification certificates. In fact, they can solve the actual work problems by properly developing the knowledge acquired. For example, the use of MITSUBISHI FR series frequency converter explained by technicians teaching, students should be able to extend and master the characteristics and usage methods of the general frequency converter so that they can use every kind of frequency converters correctly in the work. They can't use the frequency converter which is not FR series in the work, and then complain of not acquiring the real skills by obtaining vocational qualification certificates, which is only an excuse of lack of motivation to self-promotion by learning.

\section{2) Lack of perseverant learning attitude}

Many students lack perseverant learning attitude, want to attain the highest level in one step, try to master the sophisticated technology quickly by obtaining the vocational qualification certificate, and immediately find a good job. Once they have failed to realize their dreams after obtaining the vocational qualification certificate, they will have to slander vocational qualification certificates. This is actually a very short-sighted behavior, they cannot consider their own development at a height in the long run. It is a long process of continuous learning to grasp super high skills. It is long enough for students to digest, understand and integrate their knowledge into a flexible environment. Vocational qualification certificate is not only a stepping stone to their job promotion, but also a guide for their future technological development. The acquisition of vocational qualification certificate is not the end of learning and self-promotion, but the beginning of selfpromotion and development, which requires a perseverant learning attitude.

\section{CONCLUSION}

Facing "the uselessness of vocational qualification certificate", we should have a clear understanding of the causes of this argument. The policies should be formulated to enhance the social influence of vocational qualification certificates. There should be a reasonable distribution system to increase the income of employees who obtained vocational qualification certificates for enterprises. And the assessment scope of vocational qualification certificates should also closely related to the new technology development. The government should increase investment in training institutions at all levels ${ }^{[3]}$, so that the quality and hardware facilities of training institutions will be improved. As a student, we should plan our career development direction and define our career development steps and life plans. At the same time, we should guard against arrogance and impetuosity, pay more attention to improving the level of own skills, strengthen the technical accomplishment, and make us have the potential and ability to flow to a higher social level in our work.

\section{ACKNOWLEDGMENT}

This article is one of the stage achievements of the following projects: 2017 Research and practice of new engineering talents training of Electronic Information Engineering Specialty in Guangdong; 2017 the education project of university innovation and entrepreneurship in Guangzhou (No. 2017192201); 2017 Quality project of Guangdong University of Education (No. 2017zdzz01); 2017 Innovation and Entrepreneurship Education Program of Guangdong University of Education; 2016 Guangdong Provincial Key Laboratory of Precision Equipment and Manufacturing Technology project (No. PEM201604).

\section{REFERENCES}

[1] B.William. "A new vocational qualification in spirituality and health." Journal for the Study of Spirituality.vol. 8, pp.91-96, 2018.

[2] B.Anoj. "National Vocational Qualification Framework (NVQF) for Nepal: Necessity or Waste of Money? Experts' Standpoint." Journal of Training and Development,vol. 3, pp. 3-11,2017.

[3] C. Helen, et al. "The associations between personality traits, education, occupation and the occurrence of eczema in adulthood." Journal of health psychology, vol.22, pp.916-924, 2017. 